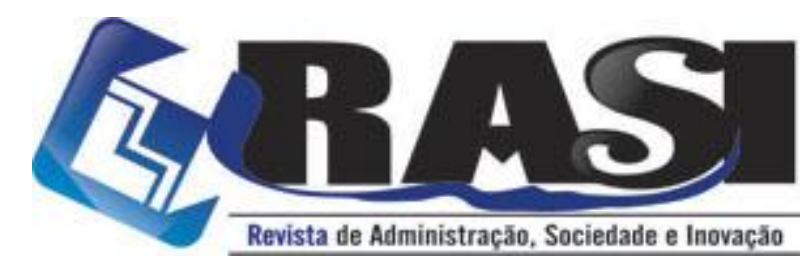

http://www.rasi.uff.br

RASI, Volta Redonda/RJ, v. 1, n. 1, pp. 21-36, Jul./Dez. 2015.

\title{
Clínica Olhar: Análise da Satisfação dos Clientes em Relação ao Serviço Prestado
}

Joyce Gonçalves Altaf - Faculdade Machado Sobrinho - jgaltaf@yahoo.com.br Danilo Machado de Matos - Universidade Federal de Juiz de Fora Letícia Tasca Tavares - Universidade Federal de Juiz de Fora Oswaldo Alves dos Santos Júnior - Universidade Federal de Juiz de Fora Regilene Imaculada Neves Lima - Universidade Federal de Juiz de Fora

Resumo: O tempo é de extrema importância na vida do homem, e a espera faz parte da rotina de todos. No setor de serviços médicos, esta espera tende a ser maior que o habitual e muitas vezes pode gerar a insatisfação do cliente. Mediante a esse constatação a prática da medicina tem lançado mão de novos mecanismos concorrenciais como o uso de um conjunto de práticas de marketing para captação e fidelização da clientela. Por consequência, torna-se necessário conhecer o cliente, investigá-lo e, mediante os resultados, oferecer opções para as organizações direcionarem ou redirecionarem suas ações, tomando por base a satisfação e a fidelidade de seus clientes. Diante disso, a presente pesquisa tem como objetivo medir a satisfação dos clientes da clínica oftalmológica Olhar em relação ao serviço prestado. Para obtenção dos resultados, foi realizada uma pesquisa de caráter quantitativo. O estudo compôs-se de quatro fases: revisão bibliográfica sobre os assuntos abordados; desenvolvimento da pesquisa com a aplicação de 153 questionários em dois turnos com clientes da clínica; análise dos resultados e conclusões e proposições para pesquisas futuras. Concluiu-se que os usuários se mostraram maciçamente satisfeitos com os serviços prestados pela clínica Olhar e pelos profissionais que nela atuam e em sua grande maioria indicariam os serviços da clínica.

Palavras-Chave: Serviços Médicos; Marketing de Serviços e Satisfação do Cliente.

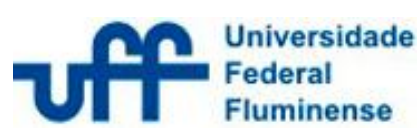

R. Desembargador Ellis Hermydio Figueira, 783, Bloco A, sl. 218, Aterrado.

27213-415 - Volta Redonda, RJ - Brasil

www.uff.br

Copyright (c) 2015 RASI. Todos os direitos, até mesmo de tradução, são reservados. É permitido citar parte de artigos sem autorização prévia, desde que seja identificada a fonte. 


\section{Clínica Olhar: Análise da Satisfação dos Clientes em Relação ao Serviço Prestado}

\section{Introdução}

Para Fitzsimmons e Fitzsimmons (2005, p. 30), “um serviço é uma experiência perecível, intangível, desenvolvida para um consumidor que desempenha o papel de coprodutor". Ao mencionar serviços, é importante conceituá-los diante das mais recentes abordagens, sem deixar de levar em consideração a sua evolução no passar dos anos: Zeithaml e Bitner (2003, p. 28) afirmam que "[...] é preciso ter consciência de que, ao longo do tempo, os serviços e o setor de serviços como um todo foram definidos de várias formas simultaneamente diferentes" conforme será abordado no presente trabalho.

A utilização do marketing de serviços nas organizações de saúde evidenciou a necessidade da preocupação com a qualidade e a confiabilidade dos serviços prestados para se obter o encantamento do cliente (paciente), a conquista de novos mercados e o reconhecimento da sociedade como ressaltou Mirshawka (1994, p. 53): "os pacientes podem se tornar bons ou maus veículos de comunicação após as experiências pelas quais passam no hospital".

Partindo da concepção de que o cliente é um fator principal na cadeia de negócio, torna-se claro a necessidade de mensuração da satisfação dos mesmos em relação ao serviço prestado. Considerando-se que um atendimento a saúde é caracterizado como prestação de serviços, é de suma importância a mensuração da satisfação em relação ao tempo de espera pelo atendimento médico. Já que os médicos na maioria das vezes não conseguem atender seus pacientes no horário, devido a diversos fatores, como, o atraso inicial do médico e até mesmo a delonga dos atendimentos, que devido a aspectos diversos, podem demorar mais do que o habitual.

Deste modo, a presente pesquisa foi desenvolvida com a finalidade de analisar até que ponto o tempo de espera pelo atendimento médico impacta na satisfação do cliente da clínica oftalmológica Olhar.

A Clínica Olhar exerce suas atividades na prestação de serviços médicos em oftalmologia, seu corpo clínico é composto por um grupo de médicos que investem em tecnologia de ponta e excelência dos serviços médicos, desta forma conseguem a satisfação do cliente, fidelizando-o e consequentemente faz um marketing com baixo custo.

Este artigo está dividido em seis partes: 1) Introdução; 2) Referencial Teórico: Marketing de Serviços, Marketing em Saúde, Qualidade em Serviços e Satisfação do Cliente; 3) Metodologia;4) Análise de Resultados; 5) Conclusão e 6) Referência Bibliográfica.

\section{Revisão Bibliográfica}

Para uma ampla compreensão dos resultados que podemos obter na pesquisa proposta por este trabalho, é preciso que primeiro tenhamos um melhor entendimento sobre o que é o marketing em serviços, como podemos aplicá-lo à saúde, os parâmetros que norteiam o conceito sobre a qualidade em serviços e principalmente os pontos que 
interferem de forma positiva ou negativa na formação da opinião do cliente em relação a sua satisfação com o serviço prestado, pois como bem conceitua Moura et al (2004), a satisfação é a relação entre a expectativa do cliente versus o serviço prestado.

Conhecendo e entendendo melhor cada passo desses tópicos, torna mais fácil para o administrador identificar quem são seus clientes, quais suas expectativas, pontos fortes e fracos de sua empresa e desse forma traçar de forma mais acertiva estratégias de marketing e de investimentos que o levem a obter máxima satisfação de seus usuários.

\subsection{Marketing de Serviços}

Pode-se observar que ao longo da história, as atividades de serviço sofreram movimentos cíclicos, uma vez que sua representatividade é relativa ao momento observado. Enquanto na Grécia clássica os serviços desempenhavam um papel econômico marginal, a partir da baixa Idade Média tornou-se essencial para uma economia sustentada por "serviços" de transporte de especiarias e tecidos. No entanto, com a primeira Revolução Industrial a importância dos serviços sofreu um declínio, sendo retomada posteriormente em meados do século XX e mantida até os dias atuais (CORREA e CAON, 2010).

Verifica-se que o crescimento do setor de serviços na economia mundial é inegável. Grönroos (1995) afirma que estamos em uma sociedade de serviço ou em uma economia de serviços. Ou seja, a participação do setor de serviços em comparação aos demais é superior em relação à mão de obra empregada e à participação no PIB (FUCHS apud GRÖNROOS, 1995). Para Fitzsimmons e Fitzsimmons (2005) os serviços estão no centro das atividades econômicas.

Salienta-se que é seguro afirmar que o Brasil está inserido nas tendências do mundo industrializado (CORREA e CAON, 2010). Estatísticas do IBGE (ANO) comprovam que o setor de serviços vem-se mantendo em torno de $65 \%$ ao longo dos últimos anos, dominando o setor industrial e agropecuário.

Diante desse fato é de suma importância entender esse setor. Para isso, diversos estudiosos debatem sobre o tema e alguns deles possuem a mesma opinião na definição de marketing de serviços, tais como a definição de "atividades operacionais destinadas a investigar, obter e servir a demanda por assistência profissional, objetivando investigar a oportunidade de mercado para planejar, organizar e oferecer assistência de serviços de qualidade, a preços razoáveis que possibilitem satisfação dos clientes e remuneração adequada aos profissionais". (CORREA e CAON, 2010; FITZSIMMONS E FITZSIMMONS, 2005; GRÖNROOS, 2004). Sua execução pode ou não estar ligado ao dinheiro. Exemplos: alugar um quarto de hotel, depositar dinheiro em um banco, cortar o cabelo, viajar de avião, aconselhar-se com um advogado - todas essas atividades envolvem a compra de um serviço.

O marketing de serviços apresenta-se como meio de sobrevivência e crescimento para as empresas modernas. Seja no segmento B2B (empresas para empresas) ou mesmo diretamente aos clientes, as organizações têm cada vez mais a necessidade de repensar continuamente suas formas de atuação no mercado, já que pensar em marketing de serviços é pensar em ganho financeiro e/ou de imagem, através de um bom desempenho.

No sentido de melhorar a qualidade, a empresa deve saber identificar os critérios que os clientes utilizam para avaliar a qualidade de um serviço relativamente às expectativas. Autores como Zeithmal, Berry e Parasuraman (1985), identificaram dez 
critérios que servem de base à avaliação da qualidade dos serviços, são eles: tangibilidade, fiabilidade, rapidez, competência, cortesia, credibilidade, segurança, acessibilidade, comunicação e conhecimento do consumidor. Os mesmos autores desenvolveram o modelo SERVQUAL, modelo este, que, tem por base certas situações na prestação do serviço, que podem influenciar negativamente a percepção do cliente. Segundo eles os consumidores avaliam a qualidade do serviço comparando o que desejam receber com o que é obtido efetivamente.

Se a experiência com o produto ou serviço foi melhor do que a esperada, então o consumidor está satisfeito e a qualidade é percebida como sendo alta, mas se o serviço ou produto que ofereço é menos que o esperado, então a qualidade é baixa e o consumidor pode estar insatisfeito. Quando o consumidor recebe o esperado pelo produto ou serviço, então corresponde às expectativas. Existem alguns fatores que podem influenciar na expectativa do consumidor e a percepção que ele tem sobre o serviço recebido, que podem também ajudar a entender como é qualidade percebida e solucionar problema referente à qualidade de seu produto ou serviço, buscando sempre a opinião de seu cliente para que não haja resultado negativo. (Slack; et al, 2002)

Para Gordon (1999), a parceria com os clientes surge através do compartilhamento de benefícios durante uma vida, obtidos com a identificação e criação de novos valores com clientes individuais, através de um processo contínuo. Mas fazer com que o cliente externo venha para dentro da empresa, definindo ele mesmo seus próprios interesses é necessária uma contínua colaboração entre os fornecedores, rede de varejo e clientes internos selecionados, criando assim uma estrutura para compartilhar valores mútuos, através de independência e alinhamento organizacional contínuos.

\subsection{Marketing em saúde}

Assim como o setor de serviços em geral sofreu uma serie de modificações oriundas do desenvolvimento da sociedade, as mudanças ambientais, modificações de mercado, da tecnologia e da sociedade exigiram que as organizações de saúde também modificassem sua forma de se relacionar com seu cliente.Dessa forma, devido a essas rápidas e constantes mudanças, uma nova visão de marketing foi necessária, objetivando conquistar e manter clientes. De acordo com Urdan e Urdan (2006) o marketing de valor deve ser embasado na ética, integrado com as diferentes áreas da organização, atento as mudanças ambientais e priorizar os seus clientes de forma a sempre buscar atender e satisfazer às necessidades dos mesmos.Da mesma forma Cobra e Zwarg (1987) reafirmam que a prestação de serviços na área da saúde deve almejar um atendimento de excelência proporcionando desde boa acessibilidade ate níveis satisfatórios de resolutividade das demandas do paciente/cliente.

A utilização do marketing de serviços nas organizações de saúde evidenciou a necessidade da preocupação com a qualidade e a confiabilidade dos serviços prestados para se obter o encantamento do cliente, a conquista de novos mercados e o reconhecimento da sociedade como ressaltou Mirshawka (1994, p.53): "os pacientes podem se tornar bons ou maus veículos de comunicação após as experiências pelas quais passam no hospital".

O mix de marketing (produto, preço, promoção e praça) tem sido adotado também no setor de serviços em saúde.Segundo Cunha (2006, p.4) o mix de marketing vem sendo utilizado no setor de serviços com o intuito de demonstrar a importância de 
cada elemento na formação do pilar que sustenta o relacionamento entre a empresa e o mercado.

O "Produto" em saúde envolve todo o processo de atendimento ao paciente. $\mathrm{O}$ atendimento visa satisfazer uma necessidade ou uma demanda de saúde do paciente e todo o processo envolvido nesse atendimento faz parte do produto ou afeta $\mathrm{o}$ produto.Além disso, o paciente valoriza o ambiente físico e tudo o que acontece ao seu redor antes, durante e após o atendimento em si. Embora o serviço seja um produto intangível, as organizações de saúde podem passar a percepção de qualidade a seus pacientes através de suas instalações físicas, tecnologias utilizadas e no cuidado dispensado ao pós-venda.

No que se refere à formação de "Preço" em saúde é importante que uma criteriosa análise seja feita levando em consideração as muitas variáveis que podem influenciar o conjunto de custos diretos e indiretos do processo de atendimento do paciente.

Segundo Kuazaqui e Tanaka (2008) o conceito de "Promoção" tem uma conotação popular de redução de preços ou ganho de benefícios, ao passo que para o marketing esse termo visa promover a instituição através da exposição da empresa, dos profissionais, dos serviços e dos produtos por ela oferecidos. Na área de saúde existe uma preocupação em relação aos aspectos éticos e as formas aceitáveis de se fazer a "promoção" da instituição.

Em relação ao termo "Praça" aplicado às instituições prestadoras de serviços de saúde, refere-se a gama de clientes que podem ser alcançados pelos produtos ou serviços, levando em consideração sua localização, suas instalações e todas as suas formas de atendimento, inclusive atendimentos realizados fora das instalações físicas da instituição, como por exemplo o home-care, coleta em domicílio de material para exames laboratoriais e serviços disponíveis online, como a liberação de resultados de exames via internet. (SKRABE, 2012 apud PEREIRA; REIS; DIAS 2013).

Concluindo, o conceito chave do Marketing em Serviços é realizar o atendimento com a qualidade que o cliente almeja, em local apropriado, com preço adequado e no tempo certo, ou seja, nas condições desejadas pelo consumidor.

\subsection{Qualidade em Serviços}

O conceito de qualidade é complexo e se refere a um serviço prestado em conformidade com o esperado pelo cliente/usuário (DONABEDIAN, 1984; McKEGNEY; BECKHARDT, 1982; VUORI, 1988). Da mesma forma, embora existam diversas maneiras de analisar o conceito de qualidade, existe um senso comum que define o termo como sendo o grau de excelência alcançado na execução de ações e serviços em comparação a um determinado parâmetro (PEREIRA, 2006).

Entretanto, a dificuldade reside em determinar parâmetros apropriados para esta comparação uma vez que a sociedade é dinâmica e o conhecimento está em constante evolução. Portanto, os critérios para definir um serviço como sendo de qualidade não são absolutos e nem definitivos, como concluiu Campos (2005).

De acordo com esse mesmo autor, a concepção sobre o conceito de qualidade irá variar conforme a posição ocupada por um individuo dentro do sistema de saúde. Por exemplo, o gestor de saúde tenderá a se preocupar com aspectos como rendimento, custo e eficiência. Já o colaborador da área de prestação de serviços voltará seu foco para o reconhecimento profissional, conforto e segurança no ambiente de trabalho, 
acesso a tecnologias modernas, excelência técnica, melhoria dos processos na atenção a saúde e satisfação pessoal. Em contrapartida, o usuário apresenta expectativas e necessidades de saúde que, quando atendidas satisfatoriamente, configuram-se em uma prestação de serviço de qualidade.

Segundo Garcia (1998) e Vuori (1988) a opinião do usuário a respeito da qualidade do serviço prestado não teve o seu valor reconhecido durante muito tempo devido ao fato de o usuário não possuir conhecimento técnico. Em contrapartida, Andreoli, Martins e Mari (2002) afirmam ser de extrema importância a participação da opinião do usuário na avaliação da qualidade do serviço prestado uma vez que este é coparticipante das ações médicas realizadas. Porém os autores ponderam que a opinião dos usuários está sujeita à influência de condições subjetivas como a comparação com experiências anteriores e expectativas exacerbadas, devendo então ser utilizada com certa cautela.

Alguns autores como Akerman e Nadanovsky (1992); Medronho (2006) e Pereira (2006) afirma que para a avaliação da qualidade dos serviços de saúde, o modelo mais tradicional utilizado, é o modelo Donabedian, proposto na década de 1960, embasado nos conceitos da administração clássica de eficiência, eficácia e efetividade, utilizados para definir estratégias e estabelecer critérios e padrões de mensuração da qualidade.

De acordo com Medronhoe Pereira(2006), essa avaliação pode ser realizada também partindo dos preceitos de estrutura, processo e resultado e a associação desses três fatores indicará o nível de qualidade obtido no serviço prestado. Esses três fatores se inter-relacionam da seguinte forma: a "estrutura" está ligada aos insumos disponíveis na prestação da assistência a saúde; o "processo" envolve os procedimentos realizados pelos profissionais de saúde visando reverter os recursos em resultado; e o "resultado" se refere ao impacto no paciente referente ao procedimento realizado.

Desta forma, ressalta-se a importância do envolvimento de usuários, prestadores de serviço, gestores e a organização em si para a realização da avaliação do serviço prestado e posteriormente análise e interpretação dos resultados, buscando pontuar, demarcar e estabelecer os pontos fortes e fracos e assim traçar planos e estratégias para a constante melhoria do serviço em saúde.

\subsection{Satisfação do Cliente}

Assim como as definições de serviço e qualidade, encontra-se na literatura, diversas e complexas definições que ora se complementam, ora divergem em relação ao termo "satisfação". A satisfação é definida por Moura et al,, (2004) como sendo a relação entre a expectativa do cliente versus o serviço prestado, ou seja, quanto mais um serviço atende a uma expectativa, maior a satisfação do usuário.

Milan (2005) se refere a satisfação como um constructo de valor proveniente da relação entre custos e benefícios; ou ainda como sendo a medida que avalia o desempenho global em relação às expectativas dos usuários. JáRiveros e Berne (2007) ponderam que a satisfação do cliente pode ser influenciada por diversos fatores, tangíveis e intangíveis, como por exemplo, infraestrutura, acessibilidade, humanização dos serviços, grau de acesso à informação, nível de burocracia e interação com os trabalhadores que prestam o serviço.

Corroborando com esses autores Castilho (2007), destaque que a satisfação do cliente é um importante indicador da qualidade do serviço prestado e, em se tratando de 
serviços de saúde, outros fatores devem ser considerados, como por exemplo, experiências anteriores e expectativas futuras, estilo de vida e os valores individuais e da sociedade.

Ressalta-se que, segundo apontou Espiridião et. al., (2006), além das diversas definições e termos, há também múltiplas formas de se abordar o tema "satisfação". Avaliar o serviço do ponto de vista do usuário ou a qualidade dos serviços prestados na área da saúde, são em sua maioria as formas mais utilizadas de abordagem.

De modo geral os consumidores se deparam com uma vasta opção de serviços e produtos disponíveis para atender sua necessidade ou desejo. Desta forma, cria-se por parte dos clientes uma expectativa quanto ao custo e ao prazer proporcionado por determinado serviço ou produto ambicionado conforme Kloter e Armstrong (2007).

Esses mesmos autores afirmam ainda que clientes satisfeitos tendem a se fidelizar e a compartilhar com outros, suas experiências positivas, em contra partida, clientes insatisfeitos buscam novos fornecedores e podem manchar a imagem de uma determinada empresa ou produto perante o mercado.

É de suma importância destacar que somente a partir de 1990 a opinião dos pacientes passou a influenciar nos cuidados com a qualidade nos serviços de saúde e se tornou um relevante indicador dos avanços obtidos nessa área.(HERRERAKIENGELHER, 2009). Ressalta-se que a partir dessa nova concepção, a participação dos usuários na formação de opinião a respeito da qualidade dos serviços de saúde não pode mais ser descartada e se tornou peça fundamental neste processo deixando de servir apenas como uma forma de estimular a adesão do paciente ao tratamento como comumente víamos em estudos anteriores (WILLIANS, 1994; VAITSMAN; ANDRADE, 2005).

De acordo com Donabedian (1984), a avaliação da qualidade passou a ser realizada a partir de três ângulos distintos e complementares, a saber: satisfação do paciente, avaliação do médico e da comunidade.

Para alguns autores, o conceito de avaliação esta relacionado a verificar se os objetivos propostos foram atingidos, ou seja, visa principalmente aferir resultados (COHEN; FRANCO, 1998; HARTZ, 1999). Akerman e Nadanovsky (1992) complementam que a partir dessa avaliação dos resultados torna-se possível traçar novos objetivos visando atingir a qualidade previamente almejada.

Diversos estudos foram realizados visando avaliar a satisfação dos usuários com o atendimento recebido em diferentes serviços de saúde. No estudo de Gentil, Leal e Scarpi (2003), a satisfação do paciente foi avaliada através da aplicação de um questionário logo após a consulta oftalmológica visando avaliar a resolutividade da consulta e a satisfação das expectativas dos clientes.Já o estudo de Domingues, Santos e Leal (2004) avaliou a satisfação do paciente em relação aos serviços de atenção ao parto através de um questionário fechado com cinco opções de resposta variando de "muito bom" a "muito ruim" e ainda a opção de resposta "outros", visando permitir a expressão de opiniões na forma de uma pergunta aberta.

Outros autores, Ventura e Brandt (2004) avaliaram o grau de satisfação do paciente com a instituição através da coleta de dados dos prontuários e da aplicação de um questionário fechado visando avaliar os seguintes critérios: grau de dificuldade na localização da instituição, agendamento da consulta, forma de referência, qualidade e pontualidade do atendimento nos diversos setores, validade do procedimento cirúrgico, queixa de complicações, se repetiria o procedimento na instituição e se a indicaria para pessoas conhecidas. 
Queiroz (2007) por meio de questionário semiestruturado abordou itens como: idade, estado civil, nível de escolaridade, profissão/ocupação, tipo de parto e ainda tópicos voltados a aferir a satisfação das participantes da pesquisa por meio de itens como: qualidade do serviço, o acolhimento e o acesso.

\section{Metodologia}

A pesquisa em questão caracteriza-se por sua abordagem quantitativa, em virtude de satisfazer ao paradigma clássico, que impetra a existência de um fato externo a ser examinado com objetividade, por meio da aplicação de métodos quantitativos (TERENCE e FILHO, 2006).

Já Demo (1996, p.34) insere a pesquisa como atividade cotidiana considerando-a como uma atitude, um "questionamento sistemático, crítico e criativo, [...] ou o diálogo crítico permanente com a realidade em sentido teórico e prático".

A coleta dos dados necessários para a realização da pesquisa se efetivou através de um questionário estruturado, composto por 25 questões fechadas, onde cada pergunta concedia ao entrevistado múltiplas opções de resposta. Essa coleta foi realizada na clínica oftalmológica Olhar.

A clinica oftalmológica Olhar foi fundada em 14 de maio de 1994 por um grupo de médicos oftalmologistas de Juiz de Fora - MG. Esse grupo de médicos estava inconformado com a necessidade de os pacientes terem que sair da cidade para realizar exames complementares de oftalmologia, o que ocasionava a demora nos diagnósticos e dificultava o início do tratamento. Devido a essas questões os médicos iniciaram as ações para a formação do grupo e traçaram metas do futuro empreendimento, que tem como objetivo a prestação de serviços médicos em oftalmologia focado na excelência dos serviços e na tecnologia de ponta.

Esses dados foram alcançados através de uma amostra de 150 pacientes de diversas faixas etárias e gêneros que costumam frequentar a referida clínica. Destaca-se que os questionários foram aplicados por uma funcionária da clínica, que foi devidamente orientada para o procedimento.

A coleta foi realizada na sala de espera no horário de funcionamento da mesma e foram aplicados 75 questionários no período da manhã e 75 questionários no período da tarde para que fossem investigados pacientes que frequentassem turnos diferentes da clínica. A aplicação somente foi realizada com os pacientes que já haviam frequentado a clínica abordada no presente estudo pelo menos uma vez.

Em relação à composição das questões do questionário, destaca-se que a primeira parte é composta de dados demográficos e sociais que foram incluídos com o objetivo de apresentar um perfil socio-demográfico do cliente da clínica. Dentre esses dados foram selecionados: idade, sexo, renda familiar, escolaridade. Além disso, na segunda parte do questionário foram incluídas questões que estão diretamente relacionadas com a satisfação do cliente da clínica. Nessa etapa também foram coletados dados proeminentes para a determinação das variáveis latentes, tais como: qualidade percebida em serviços, tipo de serviço, satisfação em serviços, tempo de espera e recomendação de serviços.

Ressalta-se que a utilização de um grupo diverso de pacientes como amostra é conveniente para o resultado da presente pesquisa, pessoas com valores, opiniões e percepções diferentes associados à satisfação e a percepção do serviço prestado pela clínica e pelos profissionais, principalmente os médicos. 
O objetivo dessa primeira parte é a análise quantitativa. É identificar os aspectos que interferem na satisfação dos clientes da referida clínica oftalmológica . A vantagem de realizar essa avaliação quantitativa é deixar que os dados manifestem empiricamente as questões relevantes envolvidas no problema em investigação.

$\mathrm{Na}$ segunda parte serão destacadas as análises relacionadas à satisfação e a percepção dos clientes em relação aos serviços prestados pela clínica oftalmológica em questão e seus profissionais a partir das informações obtidas segundo o questionário aplicado aos clientes.

\section{Análise dos Resultados}

Os resultados do presente estudo apontaram percentualmente que o perfil dos usuários da Clínica Olhar, são em sua maioria de mulheres, atingindo 58,2\% e os homens atingem 39,2\% do universo de 149 questionários válidos, como se observa na figura 01 .

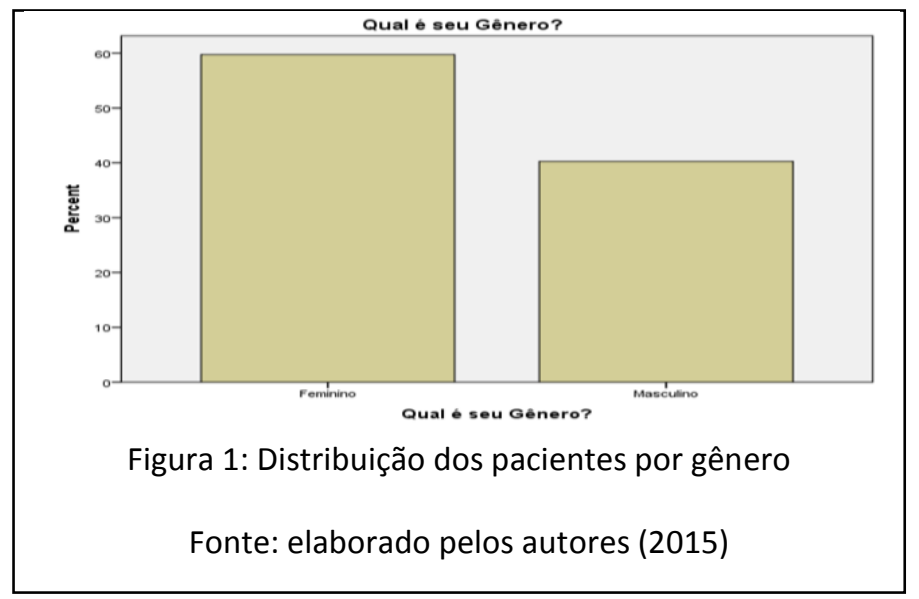

Observa-se também que quase metade dos usuários estão acima dos 65 anos de idades, equivalendo a 46,4\% do total. $26,1 \%$ estão entre 51 e 64 anos e $12,4 \%$ estão entre 40 e 50 anos de idade. As demais faixas etárias somam 12,5\% variando de menos de 12 até 39 anos de idade, vide figura 02. 


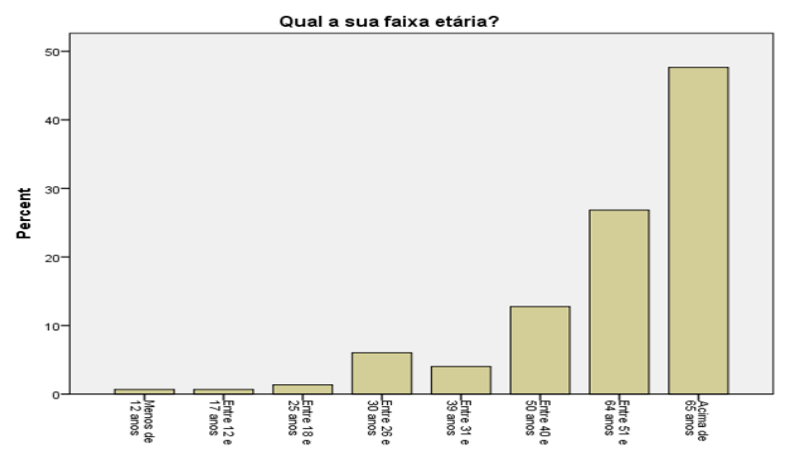

Figura 2: Distribuição dos pacientes por faixa etária

Fonte: elaborado pelos autores (2015)

Em relação ao grau de escolaridade, observamos que $27,5 \%$ dos entrevistados apresentam ensino superior completo ou acima, 47,7 ensino médio completo, 3,3\% ensino médio incompleto, 13,7 ensino fundamental completo e 5,2\% ensino fundamental conforme

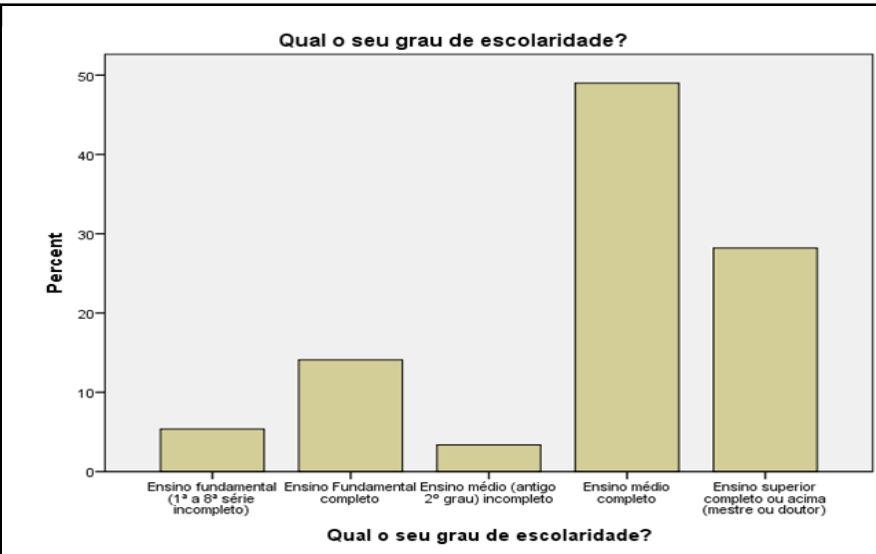

incompleto, figura 03.

Figura 3: Distribuição dos pacientes por grau de escolaridade Fonte: elaborado pelos autores (2015)

A renda familiar que poderia variar de um salário mínimo, a mais de 20 salários mínimos, teve sua maioria na faixa entre 1 e 3 salários mínimos com 37,9\% e 4 e 6 salários mínimos com $35,9 \%$, sendo que somados totalizam $73,8 \%$ do total. $15 \%$ apresentaram renda média entre 7 e 10 salários mínimos, 4,6\% apresentaram renda média de apenas 1 salário mínimo e a minoria apresentava renda familiar superior a 20 salários responsável por universo de válidos. Figura

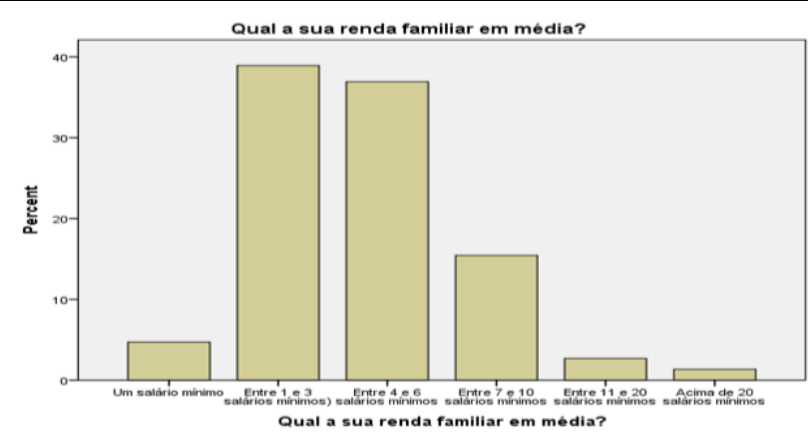

Figura 4: Distribuição dos pacientes por renda familiar Fonte: elaborado pelos autores (2015) mínimos, $1,3 \%$ do questionários 04 
Os pacientes da clinica, quando questionados há quanto tempo são clientes da mesma, 38,6\% responderam ser há mais de 5 anos, 12,4\% de 3 a 5 anos, 23,5\% de 1 a 3 anos, $17,6 \%$ há menos de 1 anos e 5,2\% há menos de 6 meses. Figura 05

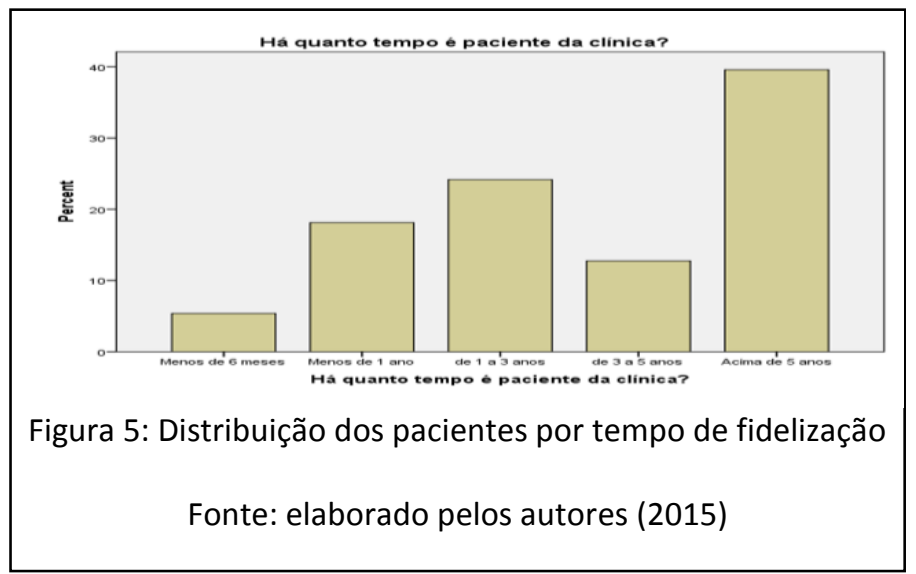

Quanto a satisfação geral perante o atendimento prestado, 91,5\% responderam ser muito bom ou bom,(sendo 55,6 para muito bom e 35,9\% para bom), 5,2\% avaliaram como regular e apenas $0,7 \%$ como ruim. Figura 06

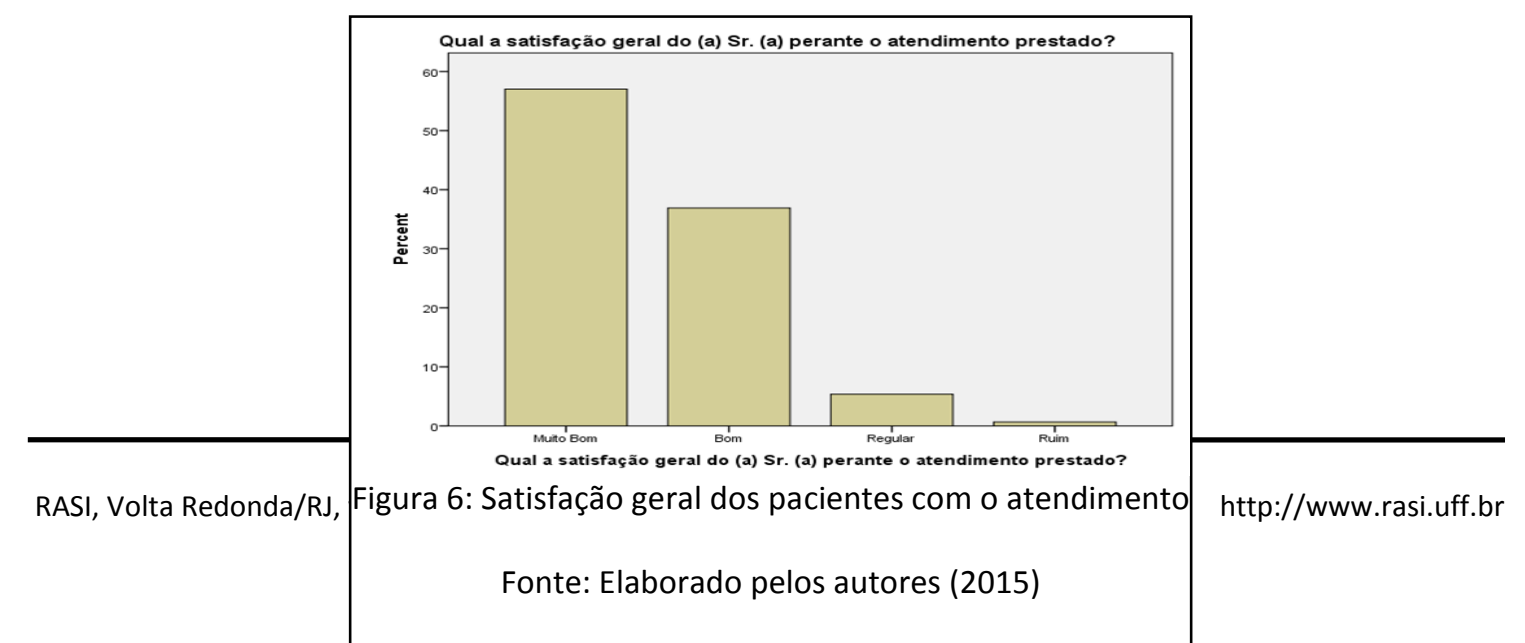


Com relação ao prazo de marcação de consultas e retorno para exames, aproximadamente $14 \%$ consideram muito bom, cerca de 59,5\% consideram bom, $23 \%$ consideram regular e $1 \%$ consideram ruim. Figura 07

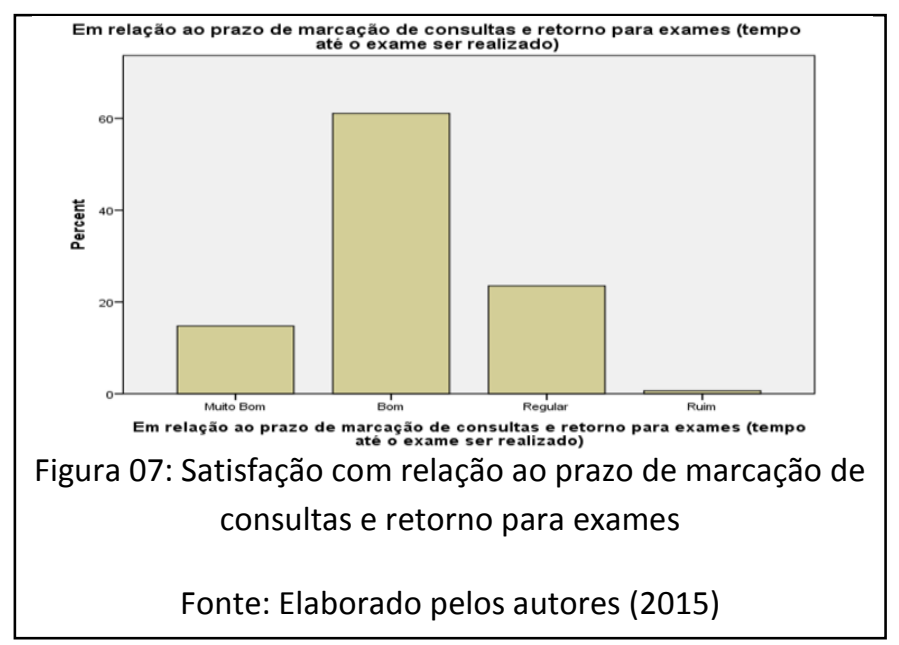

Com relação se o cliente indicaria os serviços da clínica a outras pessoas, encontramos um resultado muito importante, cerca de $91 \%$ indicaria nossos serviços a outras pessoas e 6,5\% não indicaria os nosso serviços a outras pessoas. Figura 08

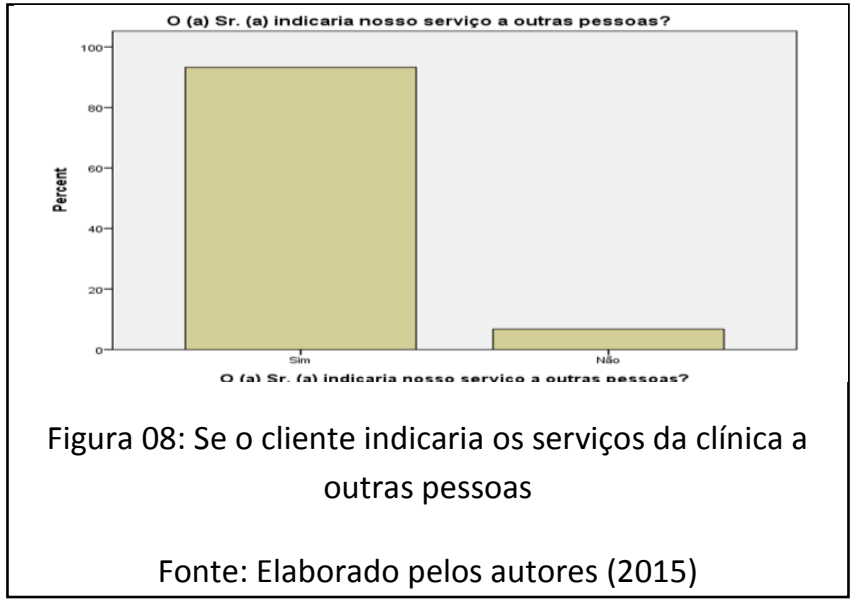

Em relação à satisfação com o tempo de espera para serem atendidos, cerca de $74 \%$ consideram que o tempo é bem aproveitado e $23,5 \%$ consideram que o tempo não é bem aproveitado e que perdem muito tempo aguardando para serem atendidos. Figura 09 


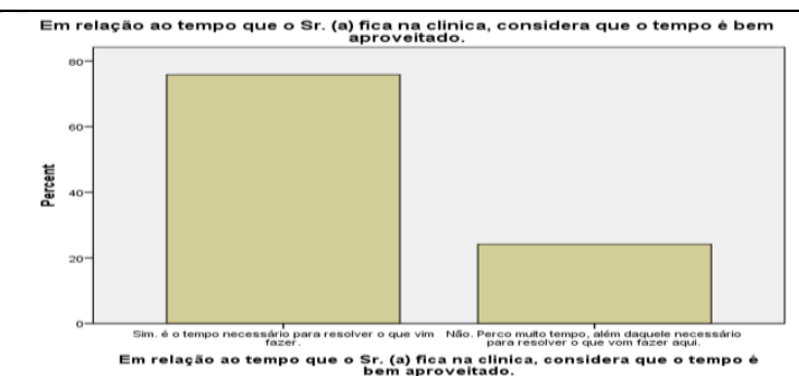

Figura 09: Em relação a se o cliente considera bem aproveitado o tempo em que permanece na clinica Fonte:

Elaborado pelos autores

Em relação a pergunta se os serviços da clínica foram recomendados por algum parente, amigo, conhecido ou colega de trabalho, 66\% dos entrevistados responderam que não receberam nenhuma recomendação e $31 \%$ receberam recomendações dos serviços oferecidos pela clínica. Figura 10

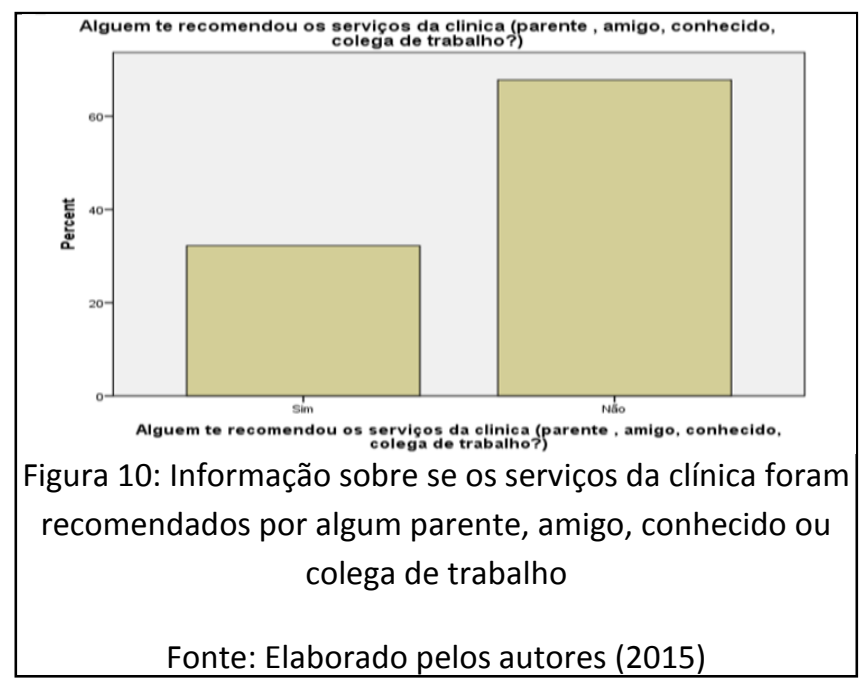

No que se refere a pergunta como se tornou paciente da Olhar ou do seu médico, averiguou-se que, dentre as principais maneiras, cerca de $23,5 \%$ dos clientes se tornaram clientes através do catálogo do convênio, 19,6\% foi por indicação de parente ou amigo e $19 \%$ por indicação de outro médico e 35,5 não especificaram a forma pela qual se tornaram clientes. Figura 11 


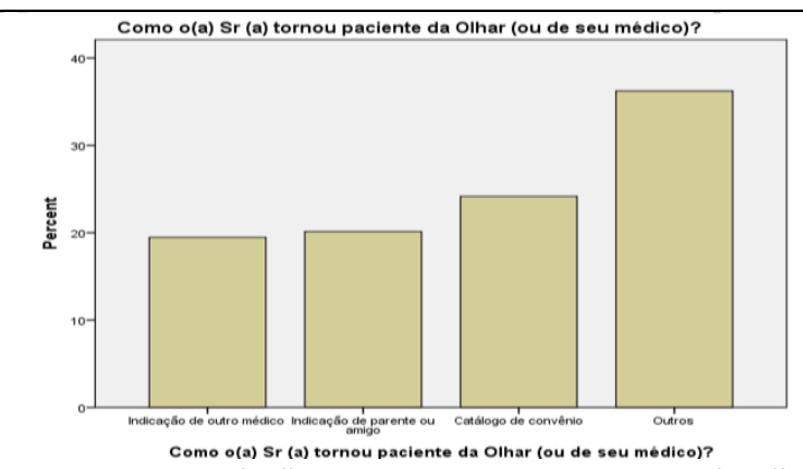

Figura 11: Em relação a como se tornou paciente da Olhar

Fonte: Elaborado pelos autores (2015)

Sobre o grau de satisfação com o atendimento médico, 73,2\% dos clientes consideram o atendimento muito bom, $23,5 \%$ avaliaram como bom e aproximadamente $0,7 \%$ disseram achar ruim. Figura 12

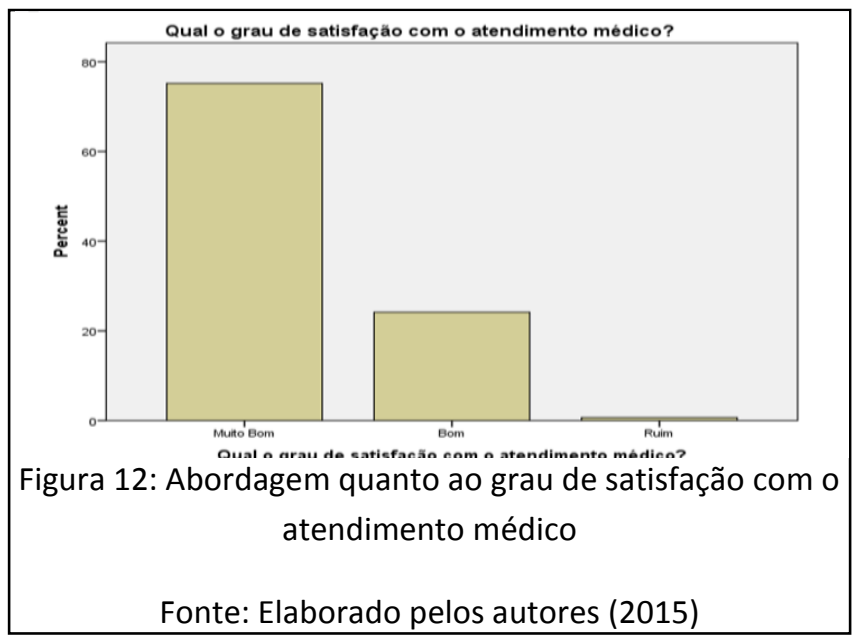

\section{Conclusão}

A realização do presente estudo apresentou grande importância quanto à descoberta, pela visão do cliente, na satisfação dos serviços prestados pela clínica oftalmológica Olhar. O desenvolvimento da pesquisa se justifica pela necessidade de se avaliar o nível de satisfação de seus clientes perante os serviços prestados. 
Após a análise dos resultados, observamos que o perfil demográfico dos usuários da clínica Olhar, é predominantemente de pacientes com idade acima de 51 anos, mulheres, com renda familiar entre 1 e 6 salários-mínimos e ensino médio completo.

Estes usuários se mostraram maciçamente satisfeitos com os serviços prestados pela clínica Olhar e pelos profissionais que nela atuam e conforme apontou Espiridião et. al., (2006), avaliar o serviço do ponto de vista do usuário ou a qualidade dos serviços prestados na área da saúde, são em sua maioria as formas mais utilizadas de abordagem do assunto.

Quando abordados sobre tempo de fidelização à clinica Olhar, quase $40 \%$ dos entrevistados responderam ser clientes ha mais de 5 anos e quando questionados se indicariam a clinica a outras pessoas, mais de $90 \%$ responderam que sim. Estes números vão ao encontro da afirmação de Kloter e Armstrong (2007) na qual aponte que clientes satisfeitos tendem a se fidelizar e a compartilhar com outros suas experiências, sejam elas positivas ou negativas.

Porém observamos ainda que uma significativa parcela de clientes, cerca de $66 \%$, tornaram-se clientes da clínica Olhar sem ter recebido qualquer tipo de indicação e tomaram conhecimento da existência da clinica por outros meios, como por exemplo, através de catálogos de convênios.

Finalmente ressalta-se que os benefícios deste trabalho consistem principalmente na possibilidade de entregar à clinica Olhar os resultados obtidos na pesquisa que foram em geral positivos.

Sugerimos ainda que tal questionário seja reaplicado periodicamente a fim de avaliar se o grau de satisfação dos clientes permanece o mesmo, ou ainda,realizar a aplicação deste questionário em clínicas que se destinam ao mesmo fim, buscando comparar o desempenho da clínica Olhar perante seus concorrentes.

\section{Referências}

AKERMAN, M.; NADANOVSKY, P. Avaliação dos serviços de saúde - avaliar o quê? Cad. Saúde Pública, Rio de Janeiro, v. 8, n. 4, p. 361-365, out./dez. 1992.

ANDREOLI, P. B. A.; MARTINS, L. A. N.; MARI, J. J. Satisfação do usuário médico com um serviço de interconsulta psiquiátrica e psicológica. Psiquiatria na Prática Médica, v. 34, n. 4. Centro de Estudos - Departamento de Psiquiatria - UNIFESP/EPM. 2001/2002.

BORBA, Valdir Ribeiro. Estratégias e plano de marketing para organizações de saúde.Rio de Janeiro: Cultura Médica - Guanabara Koogan, 2009.

CAMPOS, C. E. A. Estratégias de avaliação e melhoria contínua da qualidade no contexto da Atenção Primária à Saúde. Rev Bras Saúde Materno Infantil, Recife, v.5, supl 1, p. S63-S69, 2005.

CARDOSO, L,H,P; ANDRADE, M,A,M; GOSLING, M; ANDRADE, M,A,M. Satisfação do Usuário no Âmbito dos Serviços de Saúde: As Contribuições da Literatura de Marketing. Revista de Administração Hospitalar, v.10, n.3, pp. 75-92, setembro/dezembro, 2013.

CASTILLO, L. et al. Los predictores de satisfacción de pacientes en un centro hospitalario universitario. Revista Médica Chile. Vol.135, n.6, pp. 696-701, 2007.

COBRA, M,H,N; ZWARG, F, A. Marketing de Serviços: Conceitos e Estratégias. São Paulo: Mc Graw-Hill, 1987.

COHEN, E.; FRANCO, R. Avaliação de projetos sociais. Petrópolis: Vozes, 1998. 312 . 
CUNHA, Ayres. Marketing na prática médica. São Paulo : Assistência Médica São Paulo S/A, 2006.

DOMINGUES, R. M. S . M.; SANTOS, E. M.; LEAL, M. C. Aspectos da satisfação das mulheres com a assistência ao parto: contribuição para o debate. Cad. Saude Publica, v.20, supl.1, p.52-62, 2004.

DONABEDIAN, A. La ca lidade de la atención médica: definición y métodos de evaluación. México: La Prensa Mexicana, 1984. In: VAITSMAN, J.; ANDRADE, G. R. B. Satisfação e responsividade: formas de medir a qualidade e a humanização da assistência à saúde. Ciênc Saúde Coletiva, Rio de Janeiro, v. 10, n. 3, p. 599-613, jul./set. 2005.

EIGLIER, Pierre, LANGEARD, Eric, SERVUCTION- A gestão de marketing de empresas de serviços, McGraw-Hill, Portugal, 1991

ESPERIDIÃO, M. A.; TRAD, L. A. B. Avaliação de satisfação de usuários: considerações teórico-conceituais. Cad. Saúde Pública, vol.22, n.6, p.1267-1276, 2006.

GARCÍA, J. C. La satisfacción del cliente: singularidades de los servicios sanitarios. In: Gestión Sanitaria. Barcelona: Masson, 1998.

GENTIL, M. R.; LEAL, S. M. R.; SCARPI, M. J. Avaliação da resolutividade e da satisfação da clientela de um serviço de referência secundária em oftalmologia da Universidade Federal de São Paulo UNIFESP. Arquivos Brasileiros de Oftalmologia, São Paulo, v. 66, p. 159-65, 2003.

GORDON, lan. Marketing de relacionamento: estratégias, técnicas e tecnologias para conquistar clientes e mantê-los para sempre. São Paulo: Futura, 1999.

GUMMESSON, E. The New Marketing: Developing Long Term Interactive Relationship, Longe Range Planning, 1987.

HARTZ, Z. M. A. Avaliação dos programas de saúde: perspectivas teórico metodológicas e políticas institucionais. Ciênc Saúde Coletiva, Rio de Janeiro, v. 4, n. 2, p. 341-353, fev.1999.

HERRERA-KIENGELHER, L. et al. Qualidade da relação da equipe de saúde com pacientes hospitalizados, Cidade do México. Rev. Saúde Pública, vol.43, n.4, pp. 589594, 2009.

KOTLER, P.; ARMSTRONG, G. Princípios de marketing. 12. ed. São Paulo: Pearson Prentice Hall, 2007. 600p.

KOTLER, P., KELLER, K. - Marketing Management, Pearson - Prentice Hall, 2008. KUAZAQUI, Edmir.; TANAKA T. Luiz Carlos; Marketing e Gestão Estratégica de Serviços em Saúde. São Paulo : Thomson Learning, 2008.

McKEGNEY, F. P.; BECKHARDT, R. M. Evaluative research in consultationliasion psychiatry: review of the literature -1970-1981. Gen Hosp of Psychiatry 1982; 4: 197-218. Gen Hosp Psychiatry, New York, v. 4, n. 3, p. 197-218, Sep. 1982.

MEDRONHO, R. A. Epidemiologia. São Paulo: Atheneu, 2006.

MILAN, G. S.; TREZ, G. Pesquisa de satisfação: um modelo para planos de saúde. RAE electron. [online]. Vol.4, n.2, pp. 0-0, 2005.

MIRSHAWKA, V. Hospital: Fui bem atendido, A vez do Brasil. São Paulo: Makron Books, 1994.

MOURA, G.M.S.S.; LUCE, F.B. Encontros de serviço e satisfação de clientes em hospitais. Rev. bras.enferm., Brasília, v.57, n.4, ago. 2004. 
PEREIRA, A,C,P; REIS, L,F,A; DIAS, P,B. Os Principais Desafios para Implementação do Marketing em uma Organização Hospitalar: Caso Monte Sinai.Juiz de Fora, 2013.

PEREIRA, M. G. Epidemiologia: teoria e prática. 10. reimpressão. Rio de Janeiro: Guanabara Koogan. 2006.

QUEIROZ, M. V. O. et al. Indicadores de qualidade da assistência ao nascimento baseados na satisfação das puérperas. Texto Contexto Enfermagem, 16 (3): 479-487, 2007.

RIVEROS S, J.; BERNE M, C.. Análisis de la opinión de usuarios sobre calidad percibida y satisfacción con hospitales públicos: Estudio de caso desde la perspectiva de la aplicación del marketing. Revista Médica Chile.Vol.135, n.7, pp. 862-870, 2007.

SLACK, N.; CHAMBERS, S.; JOHNSTON, R. Administração da produção. 2. ed. São Paulo: Atlas, 2002.

URDAN, F.T; URDAN, A.T. Gestão do Composto de Marketing. São Paulo: Atlas, 2006.

VAITSMAN, J.; ANDRADE, G. R. B. Satisfação e responsividade: formas de medir a qualidade e a humanização da assistência à saúde. Ciênc Saúde Coletiva, Rio de Janeiro, v. 10, n. 3, p. 599-613, jul./set. 2005.

VUORI, H. V. El control de calidad en los servicios sanitarios. Barcelona: Masson; 1988.

WILLIAMS, B.Patient satisfaction: a valid concept? Social Science and Medicine. Vol.38, n.4, pp. 509-516, 1994. 